\title{
School-Based Intervention on Cardiorespiratory Fitness in Brazilian Students: A Nonrandomized Controlled Trial
}

\author{
Giseli Minatto ${ }^{1, * \mathbb{D}}$, Edio Luiz Petroski ${ }^{2}$, Kelly Samara da Silva ${ }^{1}$ and Michael J. Duncan ${ }^{3}$ \\ 1 Research Centre in Physical Activity and Health, School of Sports, Department of Physical Education \\ Federal University of Santa Catarina, Campus Universitário-Trindade, Florianópolis, SC 88040-900, Brazil; \\ kelly.samara@ufsc.br \\ 2 Research Centre for Kineantropometry and Human Performan, School of Sports, Department of Physical \\ Education Federal University of Santa Catarina, Campus Universitário-Trindade, Florianópolis, \\ SC 88040-900, Brazil; edioluizpetroski@gmail.com \\ 3 School of Life Sciences, Faculty of Health and Life Sciences, Coventry University, James Starley Building, \\ Priory Street, Coventry, CV1 5FB, UK; aa8396@coventry.ac.uk \\ * Correspondence: gminatto@gmail.com; Tel.: +55-48-3721-6342
}

Received: 19 December 2018; Accepted: 17 January 2019; Published: 21 January 2019

check for updates

\begin{abstract}
Background: In response to the worldwide increasing prevalence of low cardiorespiratory fitness (CRF), several interventions have been developed. The aim of this study was to examine the effect of a school-based intervention on CRF in Brazilian students. Methods: A nonrandomised controlled design tested 432 students (intervention group: $n=247$ ) from 6th to 9th grade recruited from two public secondary schools in Florianopolis, in 2015. The intervention entitled "MEXA-SE" (move yourself), applied over 13 weeks, included four components: (1) increases in physical activity during Physical Education classes; (2) active recess; (3) educational sessions; and (4) educational materials. CRF (20-m shuttle run test) was the primary outcome. Results: The effect size of the intervention on CRF was 0.15 (CI $95 \%=-0.04 ; 0.34$ ). In the within-group comparisons, $\mathrm{VO} 2 \mathrm{max}$ decreased significantly from baseline to follow-up in the control group but remained constant in the intervention group. After adjustment variables, differences between intervention and control group were not statistically significant $(p>0.05)$. Conclusion: The "MEXA-SE" intervention did not have an effect on adolescents' CRF. However, maintenance of VO2max in intervention group and a reduction within control group demonstrates that this intervention may be beneficial for long-term CRF and, possibly, the increased intervention time could result in a better effect.
\end{abstract}

Keywords: physical fitness; children; adolescents; intervention study; physical education; school health; motor activity

\section{Introduction}

Cardiorespiratory fitness (CRF) is considered an important marker of health in childhood and adolescence [1]. Low CRF has been associated with increased cardiovascular disease risk in young people [2] and adults [3]. Similarly, the maintenance of adequate CRF has been considered a protective factor for reducing the burden of mortality from cardiovascular diseases [4].

In response to the worldwide increasing prevalence of low CRF, several interventions have been developed and evaluated in recent decades [5,6]. However, the evidence of the effectiveness of school-based interventions for the promotion of CRF in low-and middle-income countries (LMICs) is limited [6,7]. Interventions implemented in the school environment prioritising CRF suggest that, regardless of study design and of the test used to measure CRF, the largest effects on CRF were found 
as a result of greater session length (>60 $\mathrm{min}$ ), frequency of three weekly sessions, programmes lasting from 13 to 24 weeks [6], and higher-intensity physical activity (PA) [5]. The literature also points to high-intensity interval training (HIIT) as a feasible and time-efficient approach for improving CRF in adolescent populations [8]. However, the embedding of HIIT within the school day (e.g., in physical education or activities adapted for the classroom) is limited [8].

In terms of intervention strategies administered within the school day, systematic reviews suggest that engagement in PA is one of the major strategies to improve CRF, with the school being a favourable environment for this $[5,6]$. The methods used to improve CRF via PA include increasing the number and intensity of physical education (PE) lessons a week; inclusion of aerobic and resistance exercises; increasing PA within and outside school [6]; and a combination of printed educational materials and changes to the school curriculum [5]. Interventions which include changes to both PE classes and another aspect of school provision (e.g., strategies of exercise/PA (effect size $=0.88 ; \mathrm{CI} 95 \% 0.55 ; 1.24$ ), PA after school time (effect size $=0.44 ;$ CI $95 \% 0.00 ; 0.87$ ) ) have reported a greater effect compared to solely PE-based strategies (effect size $=0.14 ;$ CI $95 \%-0.03 ; 0.31$ ) [6]. In this context, we applied an intervention based on the evidence previously cited, adapted to the context of schools in Southern Brazil, a low- and middle-income country (LMIC). Thus, the present study aimed to examine the effect of a school-based intervention on CRF among Brazilian students.

\section{Materials and Methods}

\subsection{Design and Participants}

The "MEXA-SE" intervention was a nonrandomised controlled trial conducted in two (one experimental) secondary major schools of the South region of Brazil. Umbrella research had the objective of analysing the effect of a multicomponent intervention, applied during one school semester (approximately four months), on health-related physical fitness and body image of students from 6th to 9th grade. A detailed description of the full trial protocol can be accessed in the trial registration (Available online: https:/ /www.clinicaltrials.gov/ct2/show/NCT02719704?term=NCT02719704\&rank=1).

According to the records of the Municipal Department of Education in 2015, 7484 students from 6th to 9th grade were enrolled in 26 public schools. The sample size calculation considered the following parameters: Effect size (ES) for each outcome, power of $80 \%$, and significance level of $5 \%$ (Table S1). Specifically, the calculation of the sample size for CRF required 35 people within each group, with an effect size of 0.68 [6]. To account for a potential 30\% loss at follow-up, 46 participants per school were necessary. Following these parameters, the sample was calculated for all primary outcomes of the umbrella research. The largest sample size required among all outcomes was 295 students (see Table S1), and this was the minimum sample established for the recruitment of schools.

School recruitment was based on the identification of the larger sample size $(n=295)$ and on the agreement of PE teachers in the intervention school to participate in the intervention. Of the 26 existing schools identified, five were eligible, two located in the Southern region (about 689 students) and three in the North (about 1165 students). For this study, the two schools (one control and one experimental) were selected in the same region of the city (Northern region) in order to reduce the possible socioeconomic disparities among students (mean of total monthly income of the people responsible for the house of each census tract of schools in Northern region $=\mathrm{R} \$ 273,321$ (approximately $\$ 73,473 ; € 64,160$ ) and Southern region $=\mathrm{R} \$ 707,416$ ) (approximately $\$ 190,166 ; € 166,060)$ ) [9]. Of the selected schools, one refused to participate and the third school from the same region was invited to participate. Contact with these schools was initiated in December 2014. The allocation of schools in the intervention (IG) and control (CG) groups was determined by authorities of the Municipal Secretariat of Education and the researchers had no influence in this decision. All participating schools were located within the urban perimeter of Florianopolis and most of the students resided near the school.

All students from grade 6th to 9th of these schools were eligible $(n=1,011)$ (records of the Municipal Department of Education). The final sample size adopted was 295 students (see Table S1); 
however, for ethical reasons and at the request of the principals of each school, the intervention was conducted with all students in the schools. In the intervention school, all students could participate in the activities offered in the "MEXA-SE" (move yourself) programme. In both the intervention and the control school, only the students who delivered parental permission were evaluated.

\subsection{Intervention}

\subsubsection{Theoretical Aspects}

The intervention strategies were developed considering previous evidence obtained via systematic review with meta-analysis [6] prepared for this purpose. The meta-analysis variables considered were CRF (primary outcome); intervention setting (school only); and strategies in intervention (actions in PE classes and one other) and control (traditional PE classes) groups. Additionally, the type of exercise for the IG (aerobic and resistance) was considered, along with session duration (minimum $45 \mathrm{~min}$ ), weekly frequency (three times), and duration of intervention (13 weeks or more).

Intervention strategies (Table 1) related to PA were developed according to the theories of health promoting schools [10], sociocognitive theory [11], and the ecological model of health promotion [12]. Body image intervention was based on the sociocognitive theory [11] and the health belief model [13], and nutritional intervention was based on the dialogical model of health education [14]. The logical model of intervention (Figure S1) was developed in accordance with the suggestions of the Center for Disease Control and Prevention [15]. The logic model includes inputs available, developed activities, outputs, influencing factors, outcomes expected in the short and long term, and the desired aim of the intervention. 
Table 1. Description of "MEXA-SE" actions.

\begin{tabular}{|c|c|c|c|c|c|c|}
\hline Actions & Influence Level & Theory & No. Sessions & Duration & WF & Executing Agent \\
\hline Training for PE teachers & School & EPS & 1 & $4 \mathrm{~h}$ & - & Researchers (PE) \\
\hline $\begin{array}{l}\text { PE Classes: Stretching exercises }(10 \mathrm{~min}) \text {, strength and } \\
\text { muscular resistance (10 min), and increased intensity in } \\
\text { the main part of the class (MVPA) }\end{array}$ & Individual & Meta-analysis & $42 *$ & $45 \mathrm{~min}$ & 3 & School PE teachers \\
\hline Active recess & $\begin{array}{l}\text { Individual, } \\
\text { School }\end{array}$ & $\begin{array}{c}\text { EPS; TSC; } \\
\text { Meta-analysis }\end{array}$ & 70 * & $15 \mathrm{~min}$ & 5 & Researchers and School \\
\hline $\begin{array}{l}\text { Educational sessions on the following topics: Health, } \\
\text { lifestyle, physical activity, and sedentary behaviour }\end{array}$ & Individual & EPS; TSC & 2 & $45 \mathrm{~min}$ & $t$ & School PE teachers \\
\hline Educational sessions on healthy eating and nutrition & Individual & MDES & 6 & $100 \mathrm{~min}$ & 1 & Researchers (Nutritionist) \\
\hline Educational sessions related to body image & Individual & $\begin{array}{l}\text { TSC; Belief in } \\
\text { health }\end{array}$ & 4 & $45 \mathrm{~min}$ & 1 & Researchers (PE) \\
\hline $\begin{array}{l}\text { Placement of posters about physical activity and } \\
\text { sedentary behaviour in school and health units }\end{array}$ & School & EPS; MSE & - & - & + & Researchers, students and teachers \\
\hline $\begin{array}{l}\text { Distribution of leaflets on physical activity and } \\
\text { sedentary behaviour }\end{array}$ & $\begin{array}{l}\text { Individual, } \\
\text { Family }\end{array}$ & EPS; MSE & - & - & tt & School PE teachers Researchers \\
\hline
\end{tabular}

PE: Physical education; WF: Weekly frequency; MVPA: Moderate to vigorous physical activity; EPS: Health-Promoting Schools [10]; Meta-analysis [6]; TSC: Sociocognitive theory [11]; MSE: Ecological social model [12]; MDES: Dialogical model of health education [14]; * We considered 14 weeks of intervention; + fixed in the 3rd and 5th week of the intervention; t+ delivered to students on the 3rd and 5th week of intervention and to parents on the 4th and 6th week. 


\subsubsection{Intervention Strategies}

The intervention employed in the current study had four integrated components that were delivered during school time in a PE class or other module.

\section{First Component: PE Classes}

The first component was to increase time spent on in moderate to vigorous PA (MVPA) during the three PE lessons per week. The three weekly classes were conducted by PE teachers in the school. The lessons were composed of approximately $10 \mathrm{~min}$ of stretching exercises, $10 \mathrm{~min}$ of strength exercises/muscular endurance, and $20 \mathrm{~min}$ of aerobic exercise, prioritising activities that arouse students' interest and in which most of them were involved in movement. The content was organised according to the Curriculum Proposal for PE of Florianopolis [16] and the National Curriculum Parameters of PE [17]. Thus, we used different content from PE (games, sports, dancing, martial arts, gymnastics) and prioritised playful aspects of learning. In total, students received an average of 25 (SD = 6.4) PE lessons (45 min per lesson).

\section{Second Component: Active Recess}

Students were also encouraged to increase PA practice during school recess. Volleyball, basketball, football, futsal, handball, and ropes were available for students to occupy the school recess time actively. These materials could be used on the school environment, such as sports courts.

Third Component: Educational Sessions

Educational sessions on "Health, Lifestyle, Physical Activity and Sedentary Behaviour": These sessions were planned by researchers and conducted by school PE teachers and lasted $45 \mathrm{~min}$ each. The first session aimed to discuss issues related to health and healthy lifestyle, seeking to identify beneficial and harmful health behaviours. The second session was aimed at discussing PA, physical exercise, and sedentary behaviour, seeking to identify the physical activities practised by students, clarifying concepts, demonstrating the importance of each behaviour for health, and reflecting on changes that everyone could do to become more active. For the development of sessions, video, educational games, and posters were used.

Educational sessions on nutrition: These sessions consisted of six sessions (45 min per session) designed to promote reflection and positive changes in eating habits and healthcare (to improve knowledge and eating habits), conducted by a nutritionist with each school year group separately. The topics developed in the sessions were: (1) Healthy eating; (2) general recommendations about the choice of foods in terms of natural and processed meals; (3) consuming a wide variety of organically grown fruit and vegetables; (4) guidelines on how to combine foods in a meal; (5) guidelines on the act of eating; and (6) a cookery workshop. The teaching methods used were movies, expository lectures, workshop context posters, music, and cooking workshops.

Educational sessions on body image: These sessions comprised three sessions (45 min per session) focused on body image satisfaction conducted by a PE researcher. The topics developed in the sessions were: (1) Beauty standards; (2) individual qualities; and (3) preparation of a poster on the theme: "What is beauty to you?". The teaching methods used were movies, expository lectures, and workshop context posters. The intervention was delivered to each class $(n=18)$ separately.

\section{Fourth Component: Education Materials}

Leaflets about sedentary behaviour and PA outcomes were distributed at the school, and two folders were sent to the parents (Figure S2) by students. The first folder had messages about reducing sedentary behaviour (recommendations, tips for changing of this behaviour, etc.), and the second on increasing PA (the importance of parental incentive, examples and benefits of active living for youths). 
The folders were also given by the PE teacher to the students with messages specific (Figure S3), along with educational sessions on these behaviours (third and fifth weeks).

School PE teachers participated in a training programme ( $4 \mathrm{~h}$ of duration) for the implementation of intervention strategies. Training consisted of an exhibition about the current context of health-related physical fitness and body image in adolescence, group dynamics that integrated physical fitness components in a practical way, and from the presentation of the intervention proposal, the role of the $\mathrm{PE}$ teacher was highlighted in the intervention and support material was delivered. In addition to training conducted with PE teachers, all school teachers participated in a 90-min meeting to present the aims and activities of the "MEXA-SE" programme.

\section{Control Group}

Both the IG and CG received the standard school curriculum as determined by the Brazilian government, which allocates $135 \mathrm{~min}$ of PE classes per week ( 3 school sessions). The mandatory PE curriculum was the content of games, sports, dancing, martial arts, and gymnastics. The school activities of the CG remained unchanged. The three weekly 45-min PE classes were conducted by PE teachers at school, following annual planning.

\subsection{Variable Measures}

CRF, the primary outcome, was assessed using the 20-m SR test using standard procedures [18], validated for Brazilian use [19]. We analysed the following indicators of 20-m SR: Laps; stages; minutes; and maximum oxygen consumption (VO2max), using the equation proposed by Leger et al [18].

Anthropometric measurements were conducted by anthropometrists certified by The International Society for the Advancement of Kinanthropometry [20]. Calculations of technical error of measurement were carried out for all anthropometric measures, which are considered acceptable for experienced evaluators [21] (height: Intra evaluator $=0.28 \%$, inter evaluator $=0.20 \%$; triceps skinfold (TR): Intra evaluator $=1.64 \%$, inter evaluator $=3.91 \%$; and subscapular skinfold $(\mathrm{SE})$ : Intra evaluator $=2.64 \%$, inter evaluator $=7.27 \%$ ).

Overall PA was self-reported using a list of MVPA validated for Brazilian adolescents (ICC $=0.88 ;$ CI 95\%: 0.84-0.91) [22] and showed a reproducibility Kappa value of 0.45 (89.3\% agreement). This list [22] included PA which was organised into different PA types: Collective PA/sports (e.g., soccer, basketball, volleyball, and indoor soccer, in 7 items), individual $\mathrm{PA} /$ sports (e.g., swimming, athletics, martial arts, and gymnastic, in 8 items), ride in PA (e.g., skateboarding/rollerblading and cycling, in 2 items), walking (i.e., leisure, transportation, and walking with dog, in 3 items), popular games (e.g., dodgeball and "forty-forty", in 2 items), and strengthening PA (e.g., weight training and abdominal exercises, in 2 items). Students reported the frequency and duration of each daily PA that they performed in the previous week. Thus, we estimated the weekly time (in minutes) of total MVPA.

The time spent in MVPA within school was measured with an Actigraph GT3X+ accelerometer, secured on the right hip by an elastic band around the waist. Wear time was determined by subtracting the time when the accelerometer was given to children (beginning of class) from the time the accelerometer was retrieved (end of class). Students wore the device for four days (from Monday to Thursday) during school time (from 7:30 to 11:30 or from 13:00 to 17:00). We considered valid data using the accelerometer for three or more days and for at least three hours per day. Data were analysed in 15-second epochs [23]. The measure used in this study to characterise the PA at school was the total minutes of MVPA, according to Everson et al [23] cut points.

Socioeconomic status (SES) was measured using a questionnaire [24]. This questionnaire estimates the purchasing power of families and ranks them from richest (A1, A2, B1, B2) to poorest $(\mathrm{C} 1, \mathrm{C} 2, \mathrm{D}, \mathrm{E})$ based on the accumulation of material goods, housing conditions, number of working individuals in the household, and the education level of the household head. The instrument provides a score for each item according to the amount present in the home and the degree of instruction of the head 
of the household. Finally, the sum of the scores obtained in all the items makes it possible to classify according to the abovementioned classes (Available online: http:/ /www.abep.org/criterio-brasil). For purposes of analysis, classes A1, A2, B1, B2 were grouped into " $\mathrm{A}+\mathrm{B}$ ", and $\mathrm{C} 1, \mathrm{C} 2, \mathrm{D}, \mathrm{E}$ were grouped into " $\mathrm{C}+\mathrm{D}+\mathrm{E}$ ".

Sexual maturation was self-assessed by the participants by classifying their breast (girls) and genital (boys) development in five pubertal stages, as proposed by Tanner [25] and validated at the UFSC (Kendall's correlation coefficient of $0.627(p<0.01)$ for boys and $0.739(p<0.01)$ for girls) [26]. The students were classified as prepubescent (stage 1), pubescent (stages 2 to 4), and postpubescent (stage 5).

Attendance in PE lessons was registered by the PE teacher in each lesson. This procedure was conducted before the start of activities.

\subsection{Data Collection}

The data collection team was composed of professors and students of the undergraduate and graduate PE and nutrition courses. Team members received training for the application of questionnaires and for the standardisation of measurements and motor tests. The instruments were applied in the respective order: Questionnaire (first day), anthropometric measurements, 20-m SR test, and sexual maturation (second day). Data collection was performed during students' class period at school. The average duration was 10 days at baseline and at follow-up (Figure 1). It was not possible to blind the staff as to which group the assessed students belonged to because the availability of human resources was limited. It was also not possible to blind students and PE teachers to the allocation due to the intervention characteristics (different activities to those conducted in PE classes before the start of the intervention). The intervention timeline is shown in Figure 1.

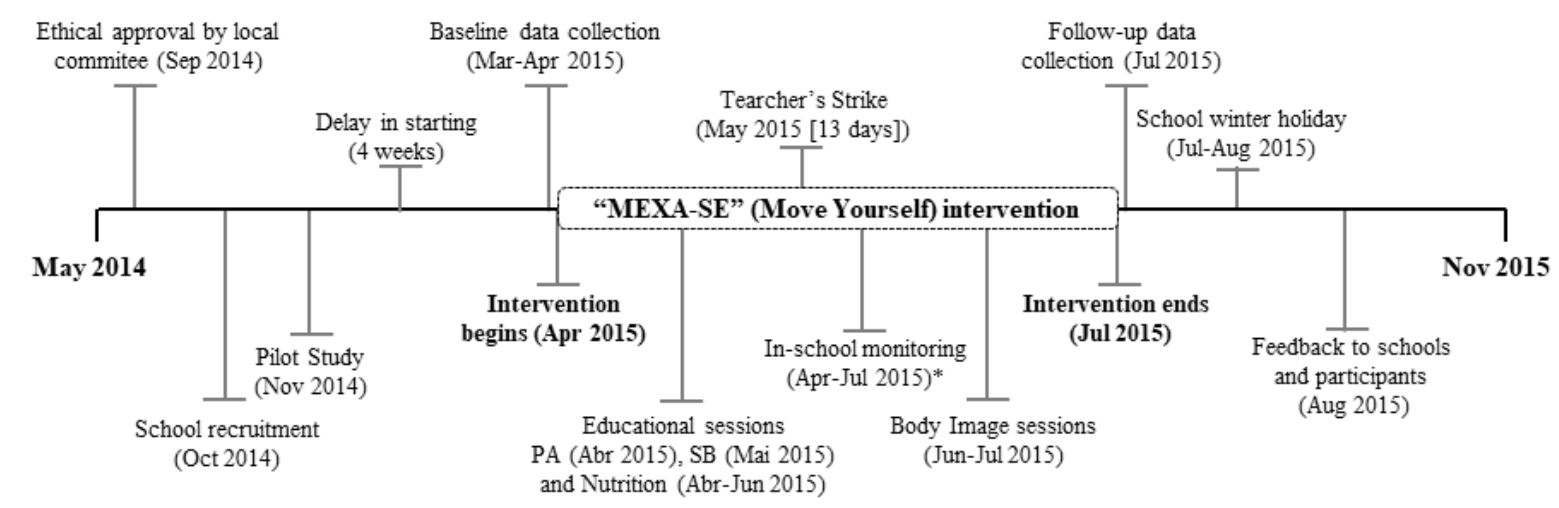

Figure 1. Timeline of the "MEXA-SE" intervention study. Note: PA: Physical activity; SB: Sedentary behaviour; *In-school monitoring comprised observations of physical education classes and school recess.

\subsection{Statistical Analysis}

Means and standard deviations were calculated at baseline and post-test for continuous variables (CRF, age, body mass, height, sum of TR and SE skinfold (TR+SE), PA in school, and overall PA). The normality of data was determined by values of skewness and kurtosis $( \pm 3)$ [27], confirmed by the display of values and histograms. The height and differences between post- and pre-test for minutes, laps, stages and VO2max showed normal distribution. The variables of body mass, TR+SE, minutes, and laps were transformed by log, VO2max by reciprocal (1/VO2max), and MVPA within school by square root. Chronological age, minutes of practice of overall PA, and stages of sexual maturation did not present normal distribution.

Mean and proportions differences between intervention and control participants at baseline were compared by independent $t$ (parametric variables) and Mann-Whitney $U$ (nonparametric variables) 
tests and chi-square analysis, respectively. To determine the effects of the intervention, analysis of covariance (ANCOVA) was used, with the change in CRF as the dependent variable, groups as the independent variable, and baseline data of CRF, sex, age group, SES, sexual maturation, overall PA, MVPA in school, and TR+SE as the covariates. The effect of the intervention was also tested from the intention-to-treat analysis (dropout data imputed by the repetition of the last observation-simple imputation) using analysis of covariance in order to assess the possible impact of sample losses in the intervention effect. In addition, we tested the interaction of all covariates with the intervention effect. We considered the existence of interaction when the $p$-value $<0.10$ [28]. The level of significance for the study was $5 \%$ for two-tailed tests using the statistical software SPSS $15.0{ }^{\circledR}($ SPSS IBM Inc., Chicago, IL, USA). The effect of the intervention on CRF was calculated for each outcome using the standardised mean difference (SMD) with a 95\% confidence interval (95\% CI) in Review Manager.

The analyses performed had a statistical power higher than $80 \%$ and $5 \%$ significance level for two-tailed tests. In the adjusted analysis of variance with group vs. time (baseline and follow-up comparisons, considering a conservative intermeasured correlation of 0.1 (Available online: http:/ /www.gpower.hhu.de/), the ES found was $\geq 0.10$.

\subsection{Ethical Considerations}

This study was conducted in accordance with the Declaration of Helsinki and it was approved by the Ethics Committee on Human Research of Carmela Dutra Maternity (process No. 780.303). The informed written consent of parents or guardians and the assent of participants were obtained.

\section{Results}

\subsection{Participants}

Of 1854 students enrolled in the five biggest schools, 1011 (two schools: 568 in IG and 443 in CG) from 6th to 9th grade (aged 9 to 16 years) were invited to take part. Of these, 568 students provided parental consent and personal assent (60.2\% in IG and 51.0\% CG). Of 568 participants, $89.8 \%$ (IG) and 93.4\% (CG) completed baseline measures. In follow-up measures, the response rate was $80.5 \%$ and $87.7 \%$ in IG and CG, respectively. Considering the time of intervention, the reasons for dropout were absence $(10.7 \%)$, giving up $(7.1 \%)$, motor limitation $(3.2 \%)$, and school change $(2.5 \%)$. Finally, 432 students (247 in the IG, 185 in the CG) participated in the study at both baseline and follow-up (Figure 2). 


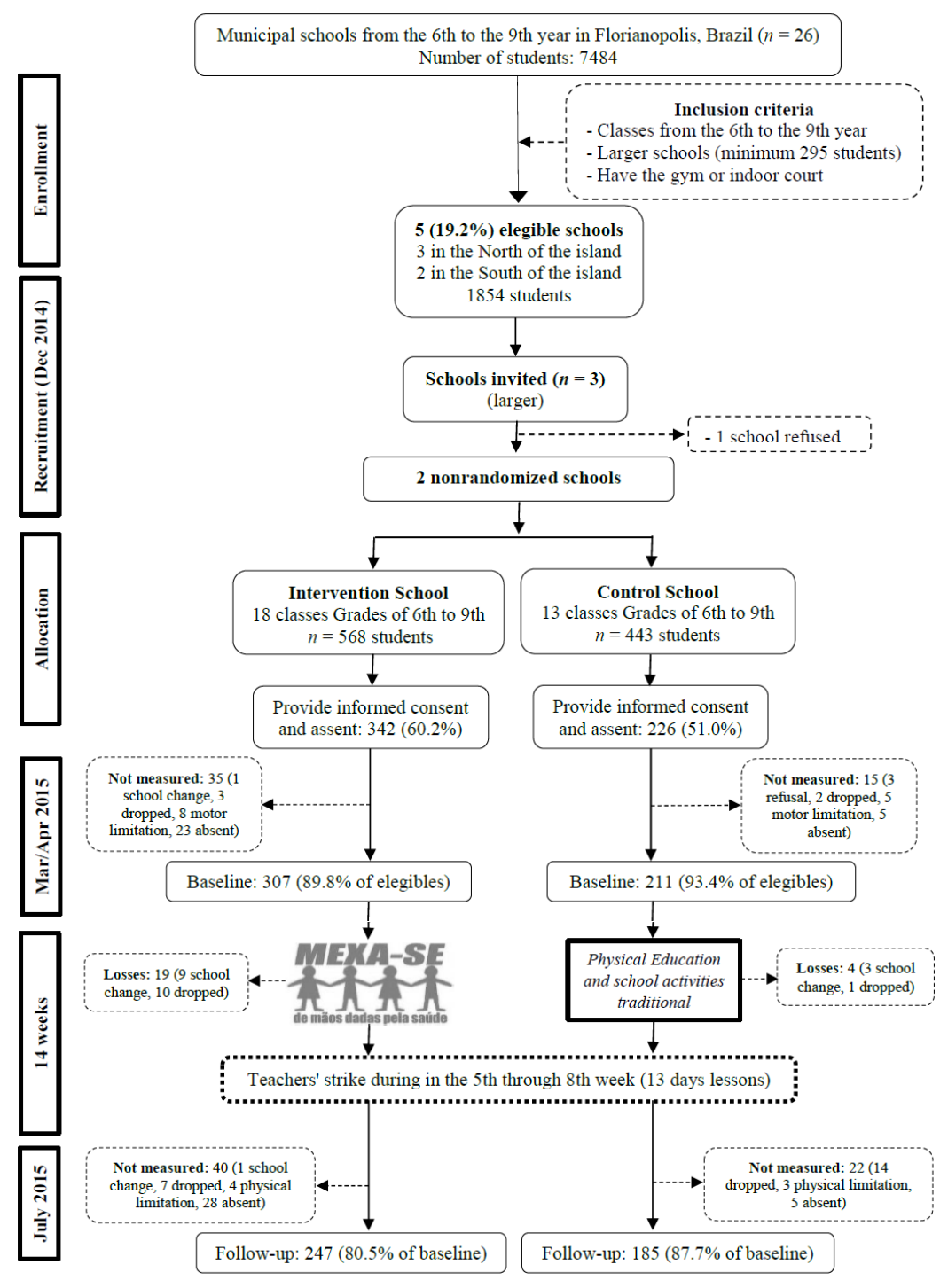

Figure 2. Flowchart of cardiorespiratory fitness. Florianopolis, Brazil, 2015. Mar: March; Apr: April; Dec: December.

\section{Deviations}

Deviations from the planned study delayed the onset of intervention by four weeks because of a delay on liberation of schools by the Municipal Department of Education; a teachers' strike from the fifth to the eighth week (13 days of lessons) of intervention also disrupted the schedule. After the delay, the intervention occurred in 11 weeks (Figure 2).

\subsection{Comparison of Baseline Characteristics}

In baseline measurements, students in the CG had greater mean values for body mass, TR+SE, attendance to PE lessons, and low performance in the CRF test than the IG $(p<0.05)$. Baseline data were also compared between dropouts and students who completed the intervention. Dropouts had greater mean values of body mass and TR+SE, and fewer minutes of MVPA practice, and less attendance of PE lessons. However, there were no differences for age, height, CRF (minutes, laps, stages, and VO2max), sex, SES, and sexual maturation variables (Table 2). 
Table 2. Baseline physical and sociodemographic characteristics, and physiological measures in intervention and control groups in Brazilian students. Florianopolis, SC, Brazil, 2015.

\begin{tabular}{|c|c|c|c|c|c|c|}
\hline \multirow[t]{2}{*}{ Variables } & $\begin{array}{c}\text { IG } \\
(n=247)\end{array}$ & $\begin{array}{c}\text { CG } \\
(n=185)\end{array}$ & \multirow[t]{2}{*}{$p$-value } & $\begin{array}{c}\text { All } \\
(n=432)\end{array}$ & $\begin{array}{l}\text { Dropout } \\
(n=136)\end{array}$ & \multirow[t]{2}{*}{$p$-value } \\
\hline & Mean (sd) & Mean (sd) & & Mean (sd) & Mean (sd) & \\
\hline Age (years) $\dagger$ & $12.4(1.3)$ & $12.7(1.3)$ & 0.052 & $12.6(1.3)$ & $12.8(1.4)$ & 0.084 \\
\hline Body mass $(\mathrm{kg})$ * & $47.7(11.3)$ & $50.2(12.4)$ & 0.047 & $48.8(11.8)$ & $52.9(13.4)$ & 0.002 \\
\hline Height $(\mathrm{cm})^{*}$ & $155.5(9.8)$ & $156.6(9.9)$ & 0.237 & $156.0(9.8)$ & $157.8(9.8)$ & 0.082 \\
\hline $\mathrm{TR}+\mathrm{SE}(\mathrm{mm}) *$ & $22.5(11.5)$ & $24.4(11.5)$ & 0.042 & $23.3(11.6)$ & 26.9 (13.3) & 0.004 \\
\hline MVPA school (min) & $10.8(6.6)$ & $10.4(6.6)$ & 0.499 & $10.8(6.6)$ & $10.1(5.6)$ & 0.833 \\
\hline PA general $(\min )+$ & $688.6(913.2)$ & $648.2(831.3)$ & 0.935 & $671.0(877.7)$ & $572.4(902.6)$ & 0.029 \\
\hline Attendance PE lessons (\%) † & $83.8(13.3)$ & $92.0(8.3)$ & $<0.001$ & $87.3(12.2)$ & $72.4(23.4)$ & $<0.001$ \\
\hline Minutes* & $3.4(1.8)$ & $3.0(1.7)$ & 0.009 & $3.2(1.8)$ & $2.9(1.5)$ & 0.093 \\
\hline Laps* & $26.4(16)$ & $22.8(13.9)$ & 0.013 & $24.8(15.2)$ & $21.9(12.3)$ & 0.077 \\
\hline Stages + & $3.8(1.9)$ & $3.3(1.7)$ & 0.007 & $3.6(1.8)$ & $3.2(1.5)$ & 0.134 \\
\hline \multirow[t]{2}{*}{$\operatorname{VO} 2 \max (\mathrm{mL} /(\mathrm{kg} \cdot \min ) *$} & $41.7(4.8)$ & $40.0(4.6)$ & $<0.001$ & $41.0(4.8)$ & $40.0(4.5)$ & 0.075 \\
\hline & $\%(n)$ & $\%(n)$ & $p$-value $* *$ & $\%(n)$ & $\%(n)$ & $p$-value ** \\
\hline Sex & & & 0.769 & & & 0.833 \\
\hline Male & $47.4(117)$ & $45.9(85)$ & & $46.8(202)$ & $47.8(65)$ & \\
\hline Female & $52.6(130)$ & $54.1(100)$ & & $53.2(230)$ & $52.2(71) \backslash$ & \\
\hline Socioeconomic Status & & & 0.190 & & & 0.385 \\
\hline$A+B$ & $54.0(129)$ & $47.5(86)$ & & $51.2(215)$ & $46.7(57)$ & \\
\hline$C+D+E$ & $46.0(110)$ & $52.5(95)$ & & $48.8(205)$ & $53.3(65)$ & \\
\hline Sexual maturationtt & & & 0.705 & & & 0.067 \\
\hline Prepubescent (S1) & $1.7(4)$ & $1.1(2)$ & & $1.4(6)$ & $1.0(1)$ & \\
\hline Pubescent (S2 to S4) & $86.8(210)$ & $89.4(160)$ & & $87.9(370)$ & $79.8(79)$ & \\
\hline Postpubescent (S5) & $11.6(28)$ & $9.5(17)$ & & $10.7(45)$ & $19.2(19)$ & \\
\hline
\end{tabular}

IG: Intervention group; CG: Control group; sd: Standard deviation; TR+SE: Sum of triceps and subscapular skinfold; PA: Physical activity; MVPA: Moderate to vigorous physical activity measured with an accelerometer; $\mathrm{m}$ : Metres; $\mathrm{kg}$ : Kilogram; mm: Millimetres; $\mathrm{VO}_{2}$ max: Maximum oxygen consumption. S: Stages; † Mann-Whitney test; †† Breasts and genitals; ${ }^{*}$ Independent $t$ student test and ${ }^{* *}$ qui-square test.

\subsection{Efect of Intervention}

The effect size of intervention was $0.15(\mathrm{CI} 95 \%=-0.04 ; 0.34)$. According of CRF indicators (Table 3), the effect size for all indicators was low and not significant $\left(\mathrm{CI}_{\text {minutes }} 95 \%\right.$ : $-0.03 ; 0.35$, $\mathrm{CI}_{\text {laps }} 95 \%$ : $-0.06 ; 0.32, \mathrm{CI}_{\text {stages }} 95 \%$ : $-0.08 ; 0.30$, and $\mathrm{CI}_{\mathrm{VO} 2 \max } 95 \%$ : $\left.-0.06 ; 0.33\right)$. In all CRF indicators, no significant differences were observed for the IG between baseline and follow-up. For the CG, only VO2max decreased significantly from baseline to follow-up. The results for adjusted differences between the IG and CG and intention-to-treat analysis were not significant. There was no interaction between the groups and sex, age, sexual maturation, and SES. 
Table 3. Effect of "MEXA-SE" intervention on cardiorespiratory fitness (CRF) among Brazilian students. Florianopolis, SC, Brazil, 2015.

\begin{tabular}{|c|c|c|c|c|c|c|c|c|c|c|c|c|c|}
\hline \multirow{3}{*}{$\begin{array}{l}\text { Indicator } \\
\text { CRF }\end{array}$} & \multicolumn{4}{|c|}{ Differences between Baseline and Follow-Up } & \multicolumn{5}{|c|}{ Adjusted Differences between Intervention vs. Control Group } & \multicolumn{4}{|c|}{ Interaction } \\
\hline & $\begin{array}{l}\text { Intervention } \\
\quad(n=247)\end{array}$ & $p$-value & $\begin{array}{l}\text { Control } \\
(n=185)\end{array}$ & $p$-value & $\begin{array}{l}\text { Adjusted } \\
\text { Difference } \\
(n=432)\end{array}$ & $p$-value & $\begin{array}{c}\text { Intention-To-Treat } \\
\text { Analysis } \\
(n=518)\end{array}$ & $p$-value & ES & $\begin{array}{c}\text { Group } \\
\text { vs. Sex }\end{array}$ & $\begin{array}{c}\text { Group } \\
\text { vs. Age }\end{array}$ & $\begin{array}{c}\text { Group } \\
\text { vs. SM }\end{array}$ & $\begin{array}{c}\text { Group } \\
\text { vs. SES }\end{array}$ \\
\hline & Mean (CI 95\%) & & Mean (CI 95\%) & & Mean (CI 95\%) & & Mean (CI 95\%) & & & $p$-value & $p$-value & $p$-value & $p$-value \\
\hline Minutes & $0.05(-0.10 ; 0.21)$ & 0.517 & $-0.11(-0.28 ; 0.06)$ & 0.206 & $0.17(-0.07 ; 0.40)$ & 0.173 & $0.13(-0.09 ; 0.34)$ & 0.257 & 0.13 & 0.351 & 0.194 & 0.558 & 0.949 \\
\hline Laps & $0.67(-0.58 ; 1.91)$ & 0.224 & $-0.83(-2.24 ; 0.57)$ & 0.291 & $1.50(-0.46 ; 3.46)$ & 0.134 & $1.16(-0.63 ; 2.95)$ & 0.202 & 0.16 & 0.477 & 0.179 & 0.759 & 0.963 \\
\hline Stages & $0.07(-0.09 ; 0.22)$ & 0.308 & $-0.06(-0.23 ; 0.11)$ & 0.497 & $0.13(-0.12 ; 0.37)$ & 0.307 & $0.09(-0.13 ; 0.31)$ & 0.430 & 0.11 & 0.122 & 0.293 & 0.894 & 0.724 \\
\hline $\mathrm{VO}_{2} \max$ & $-0.27(-0.72 ; 0.18)$ & 0.240 & $-0.75(-1.24 ;-0.24)$ & 0.004 & $0.48(-0.23 ; 1.19)$ & 0.186 & $0.40(-0.26 ; 1.05)$ & 0.232 & 0.14 & 0.107 & 0.494 & 0.900 & 0.882 \\
\hline
\end{tabular}

CI: Confidence interval; VO2max: Maximum oxygen consumption; EF: Effect size adjusted; SM: Sexual maturation; SES: Socioeconomic status; $p$-value of ANCOVA analysis adjusted by baseline CRF, sex, age group, sum of triceps and subscapular skinfold, sexual maturation, socioeconomic status, physical activity general, time in moderate to vigorous physical activity, and percentage of attendance in PE lessons (Adjustment for multiple comparisons: Bonferroni). 


\section{Discussion}

The results of the current study show that the "MEXA-SE" programme had a small but nonsignificant effect on CRF among students. We found a significant reduction in $\mathrm{VO}_{2}$ max from baseline to follow up in the CG, while no significant alteration was seen in the IG. Other indicators of CRF analysed (minutes, laps, stages, and VO2max for IG) did not differ statistically between or within groups. These results are similar to results from a cluster randomised controlled study [29] that evaluated the effect of an intervention targeting the physical and organisational school environment for noncurricular PA (SPACE) on CRF in Danish adolescents (11-14 years, mean: 6m; CI 95\%: -20; 31, p-value: 0.43 ).

Conversely, the findings of the current study are contrary to results from a nonrandomised controlled trial [30] conducted during school time in Brazilian students (10 to 15 years old). Intervention strategies were applied in PE classes twice a week for $60 \mathrm{~min}$ for one school year; the structure of PE classes comprised $30 \mathrm{~min}$ of aerobic exercise, 20 min of playing sports, and $10 \mathrm{~min}$ of stretching activities. The results for the nine-minute test were significant for CRF between groups $(E S=0.30 ; C I 95 \%=0.10 ; 0.50)$ [30]. The long duration of sessions (60 $\mathrm{min})$ and the length of intervention (one school year) [30] can explain the differences in effect size between studies with the same design (nonrandomised controlled trial) realised in Brazil. Although the weekly frequency of the study conducted in the same country (twice a week) [30] was lower than that of the present study (three times a week), the longer duration of intervention helped to overcome the resistance of the students to the new exercises.

Another reason for our results may be the duration of intervention. The intervention was planned to last 14 weeks, in line with recommendations for promoting change in this outcome [6]. However, this was not possible due to the delay of the start of the intervention (four weeks) and the teachers' strike that stopped lessons for 13 days of the intervention (from the fifth to the eighth week). The teachers' strike in Brazil also interrupted other interventions conducted with students [31]. This external factor is a reality present in Brazilian schools and is a further obstacle in promoting an improvement in physical fitness components. Researchers working in environments such as that found in Brazil should be alert to teachers' strike conditions for future interventions and might be able to mitigate the effect of such issues by planning longer interventions and/or considering the possibility of this type of interruptions. However, we do not consider that this interruption due to the teachers' strike had a meaningful impact on the results of the intervention, as similar results (no significant ES) were found in other multicomponent interventions of a longer duration [32,33].

One of the effective strategies to improve CRF highlighted in literature is the inclusion of aerobic and resistance exercises [6], and higher intensity PA in PE classes [5]. These strategies were included in the "MEXA-SE" programme. However, the fact that there is one "free lesson" per week would make it impossible to determine that this strategy is not effective. The PE teacher in the previous year used the "free lesson" system (students can do what they want during class, including staying seated) for all lessons, and with a new class structure, many students were resistant to participation; one of the three PE lessons continued in the "free lesson" system by agreement with students.

In the current study, of the $45 \mathrm{~min}$ total in the lesson, the PE teacher needed $15 \mathrm{~min}$ to record the presence and outline general content procedure before commuting to the sports field, leaving only $30 \mathrm{~min}$ to apply other content. The meta-analysis that aimed to determine the effectiveness of interventions designed to increase the proportion of PE lesson time that students spend in MVPA showed, on average, a $24 \%$ relative increase in the amount of lesson time spent in MVPA [34]. The Center for Disease Control and Prevention (CDC) [35] has previously recommended that students should be engaged in MVPA for at least $50 \%$ of PE lesson time. This information suggests that pedagogical practice of the "MEXA-SE" programme was inefficient and could be improved.

Other intervention designs have shown positive effects on the CRF promotion, particularly those using HIIT [8]. Meta-analysis regarding the utility of HIIT to improve CRF in adolescents evidenced the little heterogeneity $\left(\mathrm{Q}=9.77, \mathrm{I}^{2}=28.3 \%, p=0.202\right)$, and a large ES ( $d=1.05, \mathrm{CI} 95 \% 0.36$ to 1.75$)$. Ten $\min$ 
of HIIT training has shown to have comparable results to $40 \mathrm{~min}$ of moderate aerobic training [8]. Although the evidence of embedding HIIT within the school day is limited, this type of intervention has the potential to improve CRF in adolescent populations [8,36].

The findings from the CG identify that standard PE lessons and other activities did not contribute to improving the CRF of Brazilian students, and a reduction in VO2max was identified in the present study. In addition, attendance in PE lessons was higher for the CG compared to the IG. These results confirm the hypothesis that standard school activities, including PE lessons, do not add sufficient resources to promote and/or maintain CRF in students. Investigations into PE lessons in Brazil showed the reality of exercise in schools, i.e., the reduced mean duration of the lessons ( $35.6 \mathrm{~min}, \mathrm{SD}=6.0$ ) and low mean proportion of time spent in MVPA $(32.7 \%, \mathrm{SD}=25.2$ or $12.3 \mathrm{~min}, \mathrm{SD}=9.7)$ [37]. This directly affects one of main settings to contribute to improvement of physical fitness [6], because for organic adaptations to occur as a result of PA, individuals should be subjected to moderate and/or intense efforts taking place over a certain period [36]. Considering that the only difference between the IG and CG was the exposure to the intervention, another possible explanation for these results is the reduction in CRF that naturally happens with advancing age [38].

There are, of course, some limitations in this study. Firstly, the design was nonrandomised, because school assignment to the intervention group was made intentionally by the local educational authorities. Secondly, we were unable to conduct the study 'double-blind' because the intervention consisted of such a combination of obvious changes and activities that the data collection staff (as well as the students and PE teachers) would certainly be aware of which person or school was in which study condition. Thirdly, the intervention started four weeks later than anticipated and during the intervention period, there was a teachers' strike (May 2015), which resulted in a gap in intervention activities of 13 days. As a consequence, the duration of intervention was 11 weeks rather than the initially planned 14 weeks. Finally, the response rate for post-testing at the IG was lower than expected due to the number of absences of students from school, possibly because data collection took place in the final week of the school semester.

This study was based on the available evidence about interventions on CRF in adolescents around the world [6]. Consequently, it contributes to the advancement of interventions on CRF in LMICs, as Brazil.

\section{Conclusions}

In conclusion, the "MEXA-SE" programme contributed to the maintenance of CRF, compared to a CG where CRF declined in the same period. On the other hand, the lack of changes in the school environment and maintenance of PE classes in the usual model cannot help to maintain this component. The results need to be interpreted with caution due to extraneous factors (e.g., delayed onset of intervention, teachers' strike, and free lessons) that occurred during intervention. This intervention should be retested to show better the real effect on the CRF of the students.

Supplementary Materials: The following are available online at http:/ / www.mdpi.com/2411-5142/4/1/10/s1.

Author Contributions: G.M. and E.L.P. participated in the planning, implementation and supervision stages of the intervention. G.M. analysed the data and drafted the first version of the manuscript, while all other authors (E.L.P., K.S.S. and M.J.D.) participated in the analysis and interpretation of data, as well as critical review of the article. All authors have read and approved the final version of the manuscript and agree with the order of presentation of the authors.

Funding: This research was funded by a grant from National Counsel of Technological and Scientific Development (CNPq), Brazil (process number 474184/2013-7); the Coordination for the Improvement of Higher Education Personnel (CAPES) in providing scholarships to GM (protocol 6674/2015-01).

Acknowledgments: The authors thank the management team: Cilene R. Martins, Juliane Berria, Luiz R.A. Lima, Jéssika A.J. Vieira, André Machado, Márcia C. Simões, and Everson A. Nunes. The authors thank the executing team: Alexsandra S. Bandeira, Amanda M. George, Ana Maria Zofoli, Atanael Rodrigues, Bruno G.G. Costa, Carlos A.S. Alves Junior, Cecília Bertuol, Dominique S. Silveira, Estela A. Monego, Fabiana C. Sherer, Gabriel de Oliveira, Geyson R. Zilch, Jaqueline A. Silva, Lays T. Gripa, Lidiane A. Bevilacqua, Marina S.S. Athayde, Natalia Dias, Marcus V.V. Lopes, Pablo M. Silveira, Priscila C. Martins, Rafaela Castelini, Rodrigo Werlich. We would like to 
extend thanks to the Municipal Education Department of Florianopolis for authorising the performance of the study; to all members of the school community (managers, teachers, parents and students) of schools involved for the support during the program's implementation; to Mário R. Azevedo Junior, for the technical contributions in the preparation of the booklet for Physical Education teachers and for the exchange of experiences related to the intervention study "Physical Education +"; to the "Fortaleça sua Saúde" project for the materials provided, to Danieli V. Rebolho for the elaboration of the "MEXA-SE" logo; to Ricardo C. Gomes for the preparation of leaflets and posters, to Ricardo Marcon for the creation of the software to generate individual reports, to Lamartine Teixeira for the donation of office supplies, to the Sports Center of the Federal University of Santa Catarina, and to Ricardo Pacheco for printing of graphic materials.

Conflicts of Interest: The authors declare no conflict of interest.

\section{References}

1. Ruiz, J.R.; Castro-Pinero, J.; Espana-Romero, V.; Artero, E.G.; Ortega, F.B.; Cuenca, M.M.; Jimenez-Pavon, D.; Chillon, P.; Girela-Rejon, M.J.; Mora, J.; et al. Field-based fitness assessment in young people: The ALPHA health-related fitness test battery for children and adolescents. Br. J. Sports Med. 2011, 45, 518-524. [CrossRef] [PubMed]

2. Moreira, C.; Santos, R.; de Farias, J.; Vale, S.; Santos, P.; Soares-Miranda, L.; Marques, A.; Mota, J. Metabolic risk factors, physical activity and physical fitness in azorean adolescents: A cross-sectional study. BMC Public Health 2011, 11, 214. [CrossRef] [PubMed]

3. Kodama, S.; Saito, K.; Tanaka, S.; Maki, M.; Yachi, Y.; Asumi, M.; Sugawara, A.; Totsuka, K.; Shimano, H.; Ohashi, Y.; et al. Cardiorespiratory fitness as a quantitative predictor of all-cause mortality and cardiovascular events in healthy men and women: A meta-analysis. JAMA 2009, 301, 2024-2035. [CrossRef] [PubMed]

4. Lee, D.-C.; Artero, E.G.; Sui, X.; Blair, S.N. Mortality trends in the general population: The importance of cardiorespiratory fitness. J. Psychopharmacol. 2010, 24, 27-35. [CrossRef] [PubMed]

5. Dobbins, M.; Husson, H.; DeCorby, K.; LaRocca, R.L. School-based physical activity programs for promoting physical activity and fitness in children and adolescents aged 6 to 18. Cochrane Database Syst. Rev. 2013, 2, CD007651. [CrossRef]

6. Minatto, G.; Barbosa Filho, V.C.; Berria, J.; Petroski, E.L. School-Based Interventions to Improve Cardiorespiratory Fitness in Adolescents: Systematic Review with Meta-analysis. Sports Med. 2016, 46, 1273-1292. [CrossRef] [PubMed]

7. Burns, R.D.; Brusseau, T.A.; Fu, Y. Moderators of School-Based Physical Activity Interventions on Cardiorespiratory Endurance in Primary School-Aged Children: A Meta-Regression. Int. J. Environ. Res. Public Health 2018, 15, 1764. [CrossRef]

8. Costigan, S.A.; Eather, N.; Plotnikoff, R.C.; Taaffe, D.R.; Lubans, D.R. High-intensity interval training for improving health-related fitness in adolescents: A systematic review and meta-analysis. Br. J. Sports Med. 2015, 49, 1253-1261. [CrossRef]

9. Brasil. Instituto Brasileiro de Geografia e Estatística (IBGE). Informação Demográfica e Socioeconômica Número 28. Indicadores Sociais Municipais. Uma Análise dos Resultados do Censo Demográfico 2010. Rio de Janeiro: IBGE. 2010. Available online: http://ibge.gov.br/home/estatistica/populacao/ condicaodevida/pof/2008_2009 (accessed on 21 January 2016).

10. Brasil. Presidente da República. Decreto $\mathrm{N}^{\circ}$ 6.286, de 5 de dezembro de 2007. Institui o Programa Saúde na Escola (PSE), e dá Outras Providências. Diário Oficial da União, P.E., Brasília, DF, 5 dez., Ed. Available online: http:/ / www.planalto.gov.br/ccivil_03/_ato2007-2010/2007/decreto/d6286. htm (accessed on 29 June 2014).

11. Bandura, A. Health promotion by social cognitive means. Health Educ. Behav. 2004, 31, 143-164. [CrossRef]

12. Bronfenbrenner, B. Ecological Models of Human Development; Elsevier: Oxford, UK, 1994.

13. Seefeldt, V.; Malina, R.M.; Clark, M.A. Factors affecting levels of physical activity in adults. Sports Med. 2002, 32, 143-168. [CrossRef]

14. Stotz, E.N. Enfoques sobre educação e saúde. In Participação Popular, Educação e Saúde: Teoria e Prática; Valla, V.V., Stotz, E.N., Eds.; Relume-Dumará: Rio de Janeiro, Brazil, 2003; pp. 11-22.

15. United States Department of Health and Human Services (USDHHS). Physical Activity Evaluation Handbook; Departament of Health and Human Services, Ed.; Centers for Disease Control and Prevention: Atlanta, GA, USA, 2002. 
16. Prefeitura Municipal de Florianopolis. Secretaria Minicipal de Educação. Departamento de Educação Fundamental. Proposta Curricular. Florianópolis, 2008. Available online: http://www. pmf.sc.gov.br/arquivos/arquivos/pdf/09_04_2018_14.01.14.62a2765c21e81be772971fd729542791.pdf (accessed on 12 June 2014).

17. Brasil; Secretaria de Educação Fundamental. Parâmetros Curriculares Nacionais: Educação Física; MEC/SEF: Brasília, Brazil, 1998; p. 114. Available online: http://portal.mec.gov.br/seb/arquivos/pdf/livro07.pdf (accessed on 10 September 2013).

18. Leger, L.A.; Mercier, D.; Gadoury, C.; Lambert, J. The multistage 20 metre shuttle run test for aerobic fitness. J. Sports Sci. 1988, 6, 93-101. [CrossRef] [PubMed]

19. Duarte, M.F.S.; Duarte, C.R. Validade do teste aeróbico de corrida de vai-e-vem de 20 metros. Rev. Bras. Cienc. Mov. 2001, 9, 7-14.

20. Stewart-Brown, S. What Is the Evidence on School Health Promotion in Improving Health or Preventing Disease and, Specifically, What Is the Effectiveness of the Health Promoting Schools Approach? WHO Regional Office for Europe: Copenhagen. Available online: http:/ / www.euro.who.int/document/e88185. pdf (accessed on 5 July 2006).

21. Gore, C.; Norton, K.; Olds, T.; Whittingham, N.; Birchall, K.; Clough, M.; Dickerson, B.; Downie, L. Certificação em antropometria: Um modelo Australiano. In Antropométrica; Norton, K., Olds, T., Eds.; Artmed: Porto Alegre, Brazil, 2005; pp. 375-388.

22. Farias Júnior, J.C.; Lopes, A.S.; Mota, J.; Santos, M.P.; Ribeiro, J.C.; Hallal, P.C. Validade e reprodutibilidade de um questionário para medida de atividade física em adolescentes: Uma adaptação do Self-Administered Physical Activity Checklist. Rev. Bras. Epidemiol. 2012, 15, 198-210. [CrossRef]

23. Evenson, K.R.; Catellier, D.J.; Gill, K.; Ondrak, K.S.; McMurray, R.G. Calibration of two objective measures of physical activity for children. J. Sports Sci. 2008, 26, 1557-1565. [CrossRef]

24. Brasil. Associação Brasileira de Empresas de Pesquisa (ABEP). Critério de Classificação Econômica Brasil. 2012. Available online: http:/ / www.abep.org/new/criterioBrasil.aspx (accessed on 5 March 2014).

25. Tanner, N.G. Growth at Adolescence; Blackwell Scientificm Publications: Oxford, UK, 1962.

26. Adami, F.; Vasconcelos, F.D.A.G.D. Obesidade e maturação sexual precoce em escolares de Florianópolis—SC. Rev. Bras. Epidemiol. 2008, 11, 549-560. [CrossRef]

27. George, D.; Mallery, P. SPSS for Windows Step by Step: A Simple Guide and Reference. 11.0 Update. Available online: http://wps.ablongman.com/wps/media/objects/385/394732/ george4answers.pdf (accessed on 8 January 2019).

28. Lubans, D.R.; Morgan, P.J.; Callister, R. Potential moderators and mediators of intervention effects in an obesity prevention program for adolescent boys from disadvantaged schools. J. Sci. Med. Sport 2012, 15, 519-525. [CrossRef] [PubMed]

29. Christiansen, L.B.; Toftager, M.; Boyle, E.; Kristensen, P.L.; Troelsen, J. Effect of a school environment intervention on adolescent adiposity and physical fitness. Scand. J. Med. Sci. Sports 2013, 23, 381-389. [CrossRef] [PubMed]

30. Farias, E.S.; Carvalho, W.R.G.; Gonçalves, E.M.; Guerra-Júnior, G. Efeito da atividade física programada sobre a aptidão física em escolares adolescentes. Revista Brasileira Cineantropometria Desempenho Humano 2010, 12, 98-105.

31. Nahas, M.V.; de Barros, M.V.; de Assis, M.A.; Hallal, P.C.; Florindo, A.A.; Konrad, L. Methods and participant characteristics of a randomized intervention to promote physical activity and healthy eating among brazilian high school students: The Saude na Boa project. J. Phys. Act. Health 2009, 6, 153-162. [CrossRef]

32. Jago, R.; McMurray, R.G.; Drews, K.L.; Moe, E.L.; Murray, T.; Pham, T.H.; Venditti, E.M.; Volpe, S.L. HEALTHY Intervention: Fitness, Physical Activity, and Metabolic Syndrome Results. Med. Sci. Sports Exerc. 2011, 43, 1513-1522. [CrossRef]

33. Singh, A.S.; Chin A Paw, M.J.M.; Brug, J.; van Mechelen, W. Short-term effects of school-based weight gain prevention among adolescents. Arch. Pediatr. Adolesc. Med. 2007, 161, 565-571. [CrossRef] [PubMed]

34. Lonsdale, C.; Rosenkranz, R.R.; Peralta, L.R.; Bennie, A.; Fahey, P.; Lubans, D.R. A systematic review and meta-analysis of interventions designed to increase moderate-to-vigorous physical activity in school physical education lessons. Prev. Med. 2013, 56, 152-161. [CrossRef] [PubMed]

35. Centers for Disease Control and Prevention (CDC). Comprehensive School Physical Activity Programs: A Guide for Schools; U.S. Department of Health and Human Services: Atlanta, GA, USA, 2013; pp. 1-65. 
36. American Colege of Sports Medicine (ACSM). Guidelines for Exercise Testing and Prescription, 9th ed.; Wolters Kluwer Health; Lippincott Willians \& Wilkins: Philadelphia, PA, USA, 2014; p. 456.

37. Kremer, M.M.; Reichert, F.F.; Hallal, P.C. Intensidade e duração dos esforços físicos em aulas de Educação Física. Rev. Saude Publica 2012, 46, 320-326. [CrossRef] [PubMed]

38. Malina, R.M.; Bouchard, C.; Bar-Or, O. Growth, Maturation and Physical Activity, 2nd ed.; Human Kinetics Books: Champaign, IL, USA, 2004. 